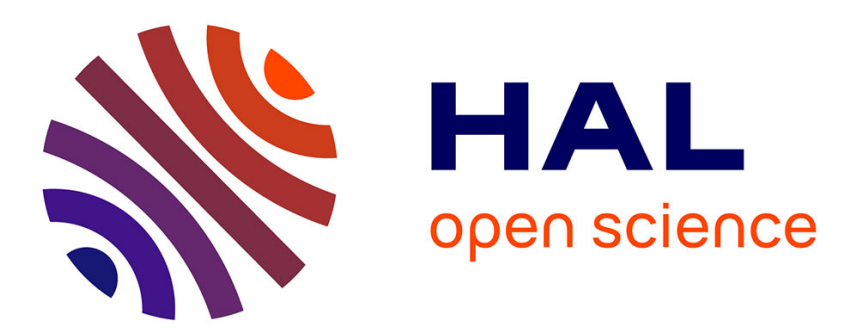

\title{
Force prediction for correction of robot tool path in single point incremental forming
}

Jérémy Belchior, Dominique Guines, Lionel Leotoing, Eric Ragneau

\section{To cite this version:}

Jérémy Belchior, Dominique Guines, Lionel Leotoing, Eric Ragneau. Force prediction for correction of robot tool path in single point incremental forming. 16th annual ESAFORM Conference on Material Forming, Apr 2013, Aveiro, Portugal. pp.1282-1289, 10.4028/www.scientific.net/KEM.554-557.1282 . hal-00872570

\section{HAL Id: hal-00872570 https://hal.science/hal-00872570}

Submitted on 27 Mar 2014

HAL is a multi-disciplinary open access archive for the deposit and dissemination of scientific research documents, whether they are published or not. The documents may come from teaching and research institutions in France or abroad, or from public or private research centers.
L'archive ouverte pluridisciplinaire HAL, est destinée au dépôt et à la diffusion de documents scientifiques de niveau recherche, publiés ou non, émanant des établissements d'enseignement et de recherche français ou étrangers, des laboratoires publics ou privés. 


\title{
Force prediction for correction of robot tool path in Single Point Incremental Forming
}

\author{
BELCHIOR Jérémy ${ }^{\mathrm{a}}$, GUINES Dominique ${ }^{\mathrm{b}}$, LEOTOING Lionel ${ }^{\mathrm{c}}$, \\ and RAGNEAU Eric ${ }^{d}$
}

Université Européenne de Bretagne, INSA-LGCGM EA-3913, 20 Avenue des Buttes de Coësmes, 35043, Rennes Cedex, France

ajeremy.belchior@insa-rennes.fr, bdominique.guines@insa-rennes.fr, clionel.leotoing@insa-rennes.fr, deric.ragneau@insa-rennes.fr

Keywords: Incremental Sheet Forming (ISF), Finite Element Analysis (FEA), force prediction, industrial robots, experimental validation

\begin{abstract}
In this work, an off-line compensation procedure, based on an elastic modelling of the machine structure coupled with a Finite Element Analysis (FEA) of the process is applied to Robotized Single Point Incremental Forming (RSPIF). Assuming an ideal stiff robot, the FEA evaluates the Tool Center Point (TCP) forces during the forming stage. These forces are then defined as an input data of the elastic robot model to predict and correct the tool path deviations. In order to make efficient the tool path correction, the weight of three numerical and material parameters of the FEA on the predicted forces is investigated. Finally, the efficiency of the proposed method is validated by the comparison between numerical and experimental geometries obtained with or without correction of the tool path.
\end{abstract}

\section{Introduction}

In order to reduce manufacturing costs and improve production versatility, serial robots can be used for industrial forming processes like Single Point Incremental Forming (SPIF) even if these structures present high compliances. The forces induced by the process lead to robot structure deflection and then to tool path errors. The TCP pose errors degrade the process results in terms of geometry, surface, etc. To correct these geometrical deviations, a compensation of the tool path is necessary.

This step can be performed by the approach described by Meier et al. in which a MBS (Multi Body System) model of the robot is coupled with a FEA of the SPIF [1]. Nevertheless, in this study the robot structure deflection is not estimated with forces calculated from the FEA but with forces measured during a first test run without any compensations. To avoid errors due to possible inaccuracies in the force prediction of analytical or numerical models, Verbert et al. chose the same strategy [2]. As explained by the authors, this strategy requires to form a dummy part which is the main drawback of this method. Most studies on the simulation of the SPIF are based on the same assumptions : thin shell elements, hardening power law, encastre boundary conditions... These models are usually efficient to predict the final shape but when force predictions are presented, they are systematically overestimated. Henrard et al. have recently studied the ability of FEA to predict the correct tool force [3]. For a frustum cone made with aluminum alloy, different numerical and material parameters have been tested. The element type and the hardening law have been identified as the more sensitive parameters. Boundary conditions applied to the FE simulation of SPIF process have also been identified as a predominant parameter by Bouffioux et al. [4].

In this work, the ability of an industrial serial robot (Fanuc S420iF) to form a part with SPIF process is studied. To improve the precision of the correction computed by the model-based approach the influence of three factors on the force level is investigated. The calculated forces are used to compute tool path correction of the robot. Finally the efficiency of the proposed coupling approach is discussed through the accuracy of the final shape regarding its nominal specifications. 


\section{Evaluation of the robot accuracy.}

A comparison of the experimental results obtained from a three axis milling machine (Famup MCX500) and the robot is done. Due to the high stiffness of the cartesian structure of the milling machine, the errors on the tool path induced by the elastic deformations of the machine can be neglected. The experimental results obtained with this machine will be considered as the reference.

Experimental setup. The part consists in a frustum cone of $45^{0}$ wall angle centered on a sheet of 200 $\mathrm{x} 200 \mathrm{x} 1 \mathrm{~mm}^{3}$. The depth of the frustum cone is $40 \mathrm{~mm}$. Figure 1(a) shows the shape of the cone. The material is a $5086 \mathrm{H} 111$ aluminum alloy. The forming tool is a hemispherical punch with a diameter of $15 \mathrm{~mm}$. In order to minimize friction, grease is used between the sheet and the tool. The infeed direction is along $\mathbf{z}_{p}$ (Figure 1(b)). The trajectory consists in successive circular tool paths at constant $\mathbf{z}_{p}$. The infeed value $\Delta_{Z}$ is $1 \mathrm{~mm}$ per loop. The clamping system (Figure 1(c)) is composed of four blank holders screwed on a rigid frame.

The robot has a payload capacity of $1200 N$. Its kinematic closed loop increases the global stiffness of the structure. Its maximum accuracy error with a load of $650 \mathrm{~N}$ applied on the TCP is about 3.2 $\mathrm{mm}$. The clamping system is fixed on a rigid table near the robot base to maximize the stiffness of the robot during the process (Figure 1(c)). The milling machine is a three axes cartesian structure. It can developed up to $7000 \mathrm{~N}$ at the end of the tool with a precision of $15 \mu \mathrm{m}$.

The force along the tool axis $\left(\mathbf{z}_{p}\right)$ is measured by strain gauge sensor fixed on the tool.After the forming process the part geometry is measured by a coordinate measuring machine.

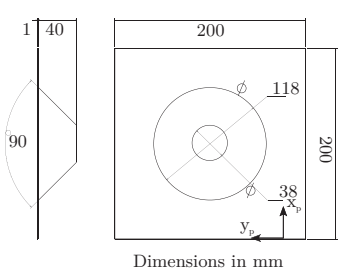

(a)

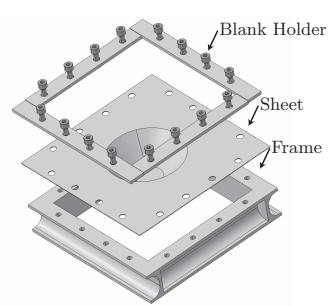

(c)

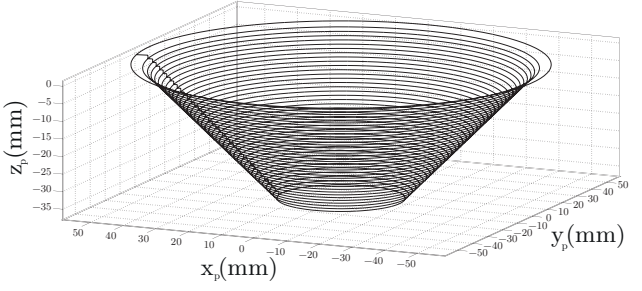

(b)

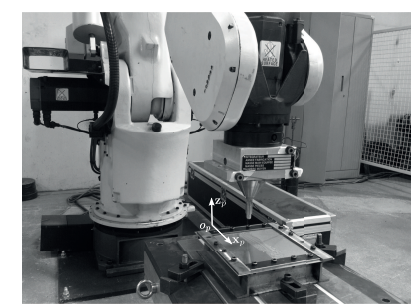

(d)

Fig. 1: Experimental setup: (a) Shape of the frustum cone, (b) Target tool path, (c) Clamping system, (d) Fanuc robot S420iF with the experimental setup

Results. The measured geometries of the frustum cone for both machines are shown in Figure 2. The part is measured along the cut axis defined in Figure 2 before the unclamping of the sheet. The maximum difference between the measured geometries of the part made with the milling machine and the robot is $4 \mathrm{~mm}$. This difference is due to the lower stiffness of the robot structure compared to the milling machine. It is confirmed by the measured forces along $\mathbf{z}_{p}$ on each machines (Figure 3). The force components are given as an average per loop. A difference of about $400 \mathrm{~N}$ is observed at the end of the trajectory, which represents $30 \%$ of the final value. Obviously these errors are not compatible with the process requirements. 


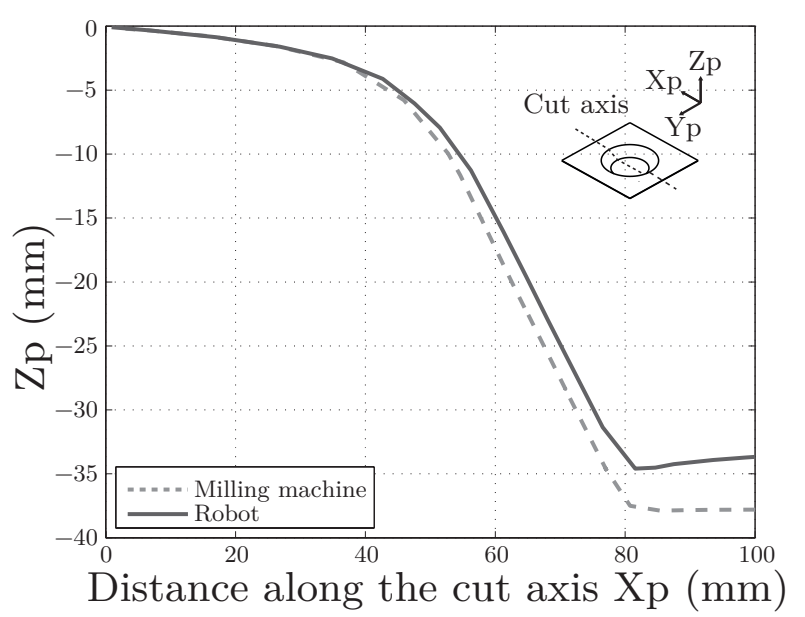

Fig. 2: Comparison of the final shape along $\mathbf{z}_{p}$.

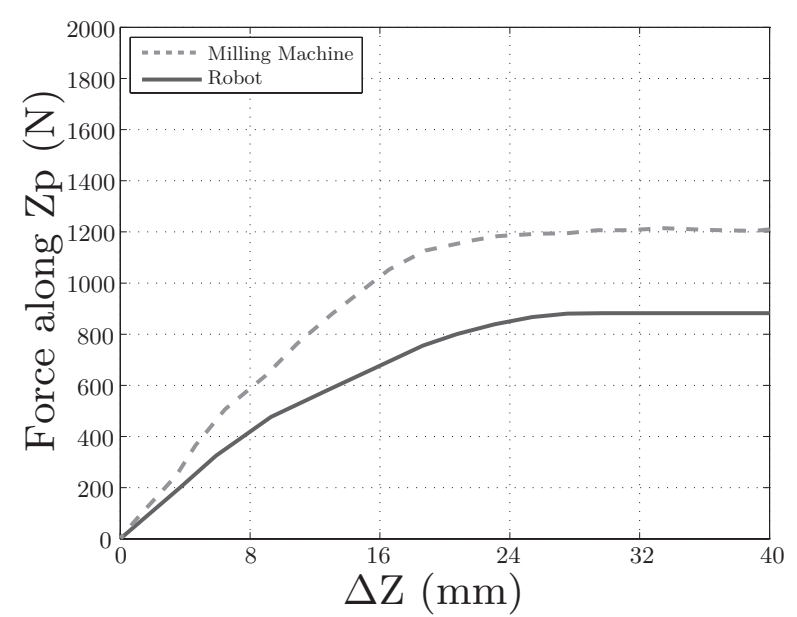

Fig. 3: Comparison of the measured force along $\mathbf{z}_{p}$.

\section{Improvement of the force prediction}

The objective of this part is to show the influence of modelling parameters on the value of the predicted force.

Model description. All the numerical simulations are done with the ABAQUS software using an implicit formulation. A $45^{0}$ pie model is chosen to minimize the computation time (Figure 4). This approach has been first used by Henrard et al. and it has been shown that the results of a whole blank and a $45^{\circ}$ pie models are very similar [3]. In particular, the maximum relative error of the axial force $F_{z}$ of the partial simulations compared to the full one was smaller than $10 \%$. Symmetry boundary conditions are applied on the $0^{0}$ and $45^{0}$ sections.

Element type and mesh. The meshing size is smaller at the contact point between the tool and the sheet over the trajectory. Two types of elements (S4R and C3D8I) are compared. The S4R element is a 4-node, quadrilateral, stress/displacement shell element with reduced integration and a large-strain formulation. It is particularly dedicated for stamping processes of thin shells and allows reduction of the computation time. The C3D8I element is a 8-node linear brick, with full integration and incompatible modes. Four elements are applied along the thickness. The main difference between the S4R and the C3D8I elements is the ability of the brick element to model the through thickness shear. When, C3D8I elements are used in the contact zone between the tool and the sheet (Figure 5), S4R elements are kept on the other areas. This 'mix model' leads to a reasonable computation time despite the use of C3D8I elements.

Boundary conditions. Two types of boundary conditions are investigated. The first consists in defining encastre boundary condition on the four edges of the sheet in contact with the clamping system. For the second case the clamping system is modeled by pressure areas applied on the contact zone between the sheet and the blank holder (Figure 6).

The pressure $(P)$ applied on each tightening areas $(S)$, is estimated from the experimental torque $C$ applied on each screw and measured by means of a torque wrench. The contact between the frame and the sheet is modeled with a friction coefficient of 0.05 . 


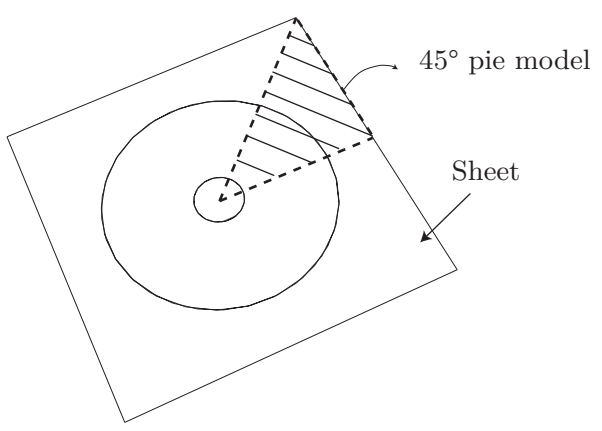

Fig. 4: Description of the $45^{\circ}$ pie model

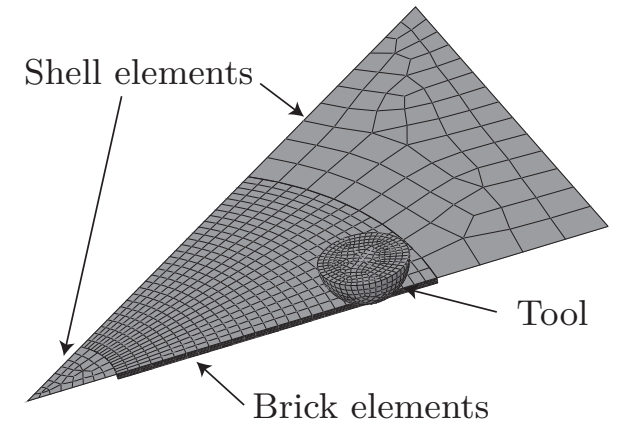

Fig. 5: Description of the mix model
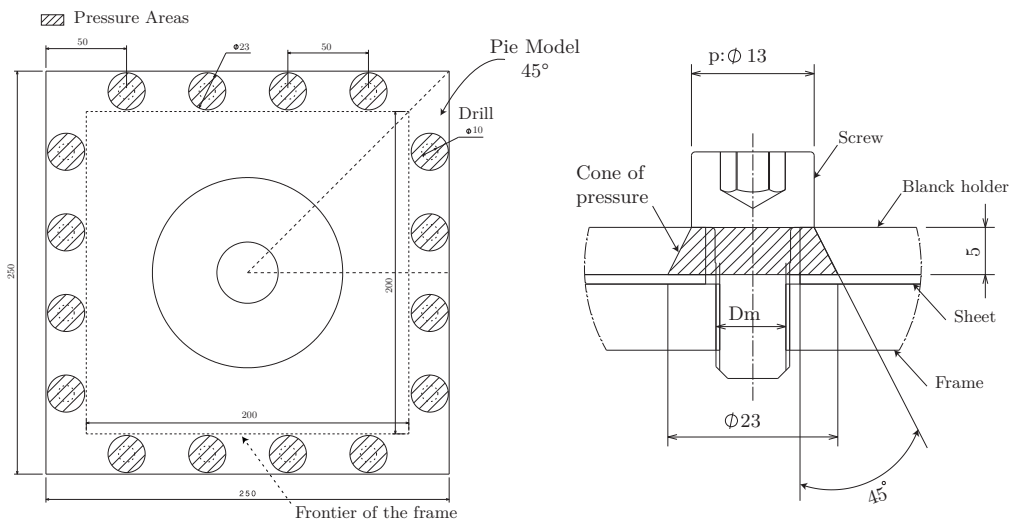

Fig. 6: Description and modelling of the clamping system

Material behavior. Based on previous works of Zhang et al., an elasto-plastic model associated with an isotropic von Mises yield criterion is used to describe the behavior of the $5086 \mathrm{H} 111$ aluminum alloy [5]. It has been shown previously that this material exhibits a quasi-isotropic plane behavior and a low transversal thickness anisotropy. The elastic behavior of the material is defined by the Young modulus $E=66 G P a$ and the Poisson ratio $\nu=0.3$.

Two different hardening laws are implemented on the model. First a Ludwick law is chosen:

$$
\bar{\sigma}=\sigma_{e}+K_{1} \cdot{\overline{\varepsilon_{p}}}^{n}
$$

with $\bar{\sigma}$ is the equivalent stress, $\sigma_{e}$ the initial yield stress $\left(\sigma_{e}=125.88 \mathrm{MPa}\right), \overline{\varepsilon_{p}}$ the equivalent plastic strain, $K_{1}=447.08 \mathrm{MPa}, n=0.413$.

Secondly a Voce law described by Diot et al. to model saturation or softening effects of aluminum alloys is used [6]. The formulation is given by:

$$
\bar{\sigma}=\sigma_{e}+K_{2} \cdot \sqrt{1-e^{\left(-B \cdot \overline{\varepsilon_{p}}\right)}}
$$

with $\sigma_{e}=130.2 \mathrm{MPa}, K_{2}=330.37 \mathrm{MPa}, B=3.94$.

The constants of the two hardening laws defined above are determined from the experimental stress/strain curve of a tensile test made in the rolling direction. This curve and the identified Ludwick and Voce laws are presented in Figure 7.

Due to the high level of deformation reached by the process, the hardening law must be chosen carefully. Figure 7 shows the strain range reached in SPIF (up to 120\%) in comparison with the strain level reached in the uni-axial tensile test (about 20\%). For high levels of deformation, it is difficult to identify accurately the hardening behavior with only a database of a uni-axial tensile test. The choice of the Voce law leads to a constant stress for strain higher than $60 \%$. On the contrary the Ludwick law presents a stiffer behavior for large strains. 


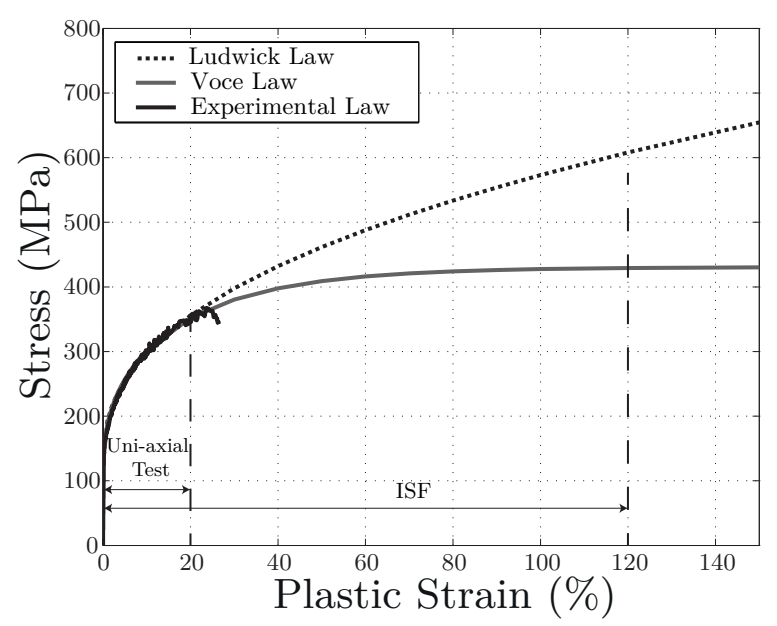

Fig. 7: Hardening laws implemented in the simulation

Models. To evaluate separately the influence of the each parameter discussed above on the force prediction three modelling configurations are proposed. The table 1 sums up the different assumptions for each model.

Table 1: Description of the compared models

\begin{tabular}{cccc}
\hline & Elements & Boundary conditions & Hardening laws \\
\hline Model 0 & Shell & Encastre & Ludwick \\
\hline Model 1 & Brick + Shell & Encastre & Ludwick \\
\hline Model 2 & Brick + Shell & Realistic & Ludwick or Voce \\
\hline
\end{tabular}

Model 0 is built with the same hypothesis generally used in the literature. Model 1 uses brick elements to model accurately the through thickness shear. Because sliding between the sheet and the clamping system can appear, Model 2 represents a more realistic clamping system with pressure areas applied on the contact zone between the sheet and the blank holder. Based on Model 2, the influence of the hardening law (Ludwick or Voce) is evaluated. For each model, the predicted force along the tool axis is compared with the experimental force value from the milling machine. The mean force at each loop of the trajectory is computed when the TCP crosses the middle axis of the $45^{\circ}$ pie model.

Influence of through thickness shear. The Figure 8 shows that the choice of thin shell elements does not give a good correlation between experimental and predictive force. The force reaches a steady state value which is the maximum level of the force. A maximum difference of approximately $750 \mathrm{~N}$ is identified which represents $40 \%$ of the final value. The predictions of Model 1 give better results. These results confirm the importance of the trough thickness shear on the force prediction. For that purpose, brick elements have to be considered. Nevertheless the prediction of the final geometry of the part is very close for both elements (Figure 9).

Influence of boundary conditions. The Figure 10 shows a comparison between the simulated forces from the two different boundary conditions. As expected, the more realistic model with the pressure (Model 2) gives a predicted force level lower than Model 1 and closer to the experiments. This modelling improves the force prediction of $55 \%$ compared to the Model 1 . However, before a value of $20 \mathrm{~mm}$ for $\Delta_{Z}$, the predicted forces is lower than the measured one. This difference is linked with a slight sliding during the simulation. 


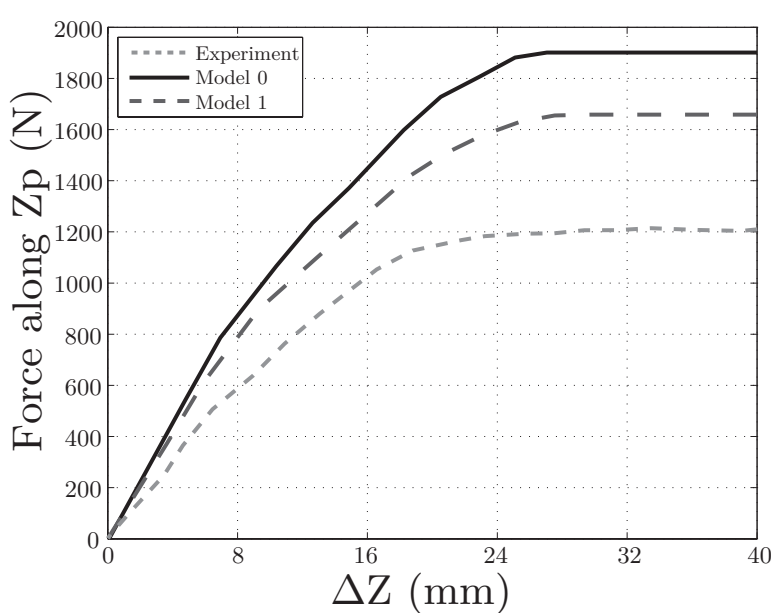

Fig. 8: Effect of the finite element type on the force $F_{z}$

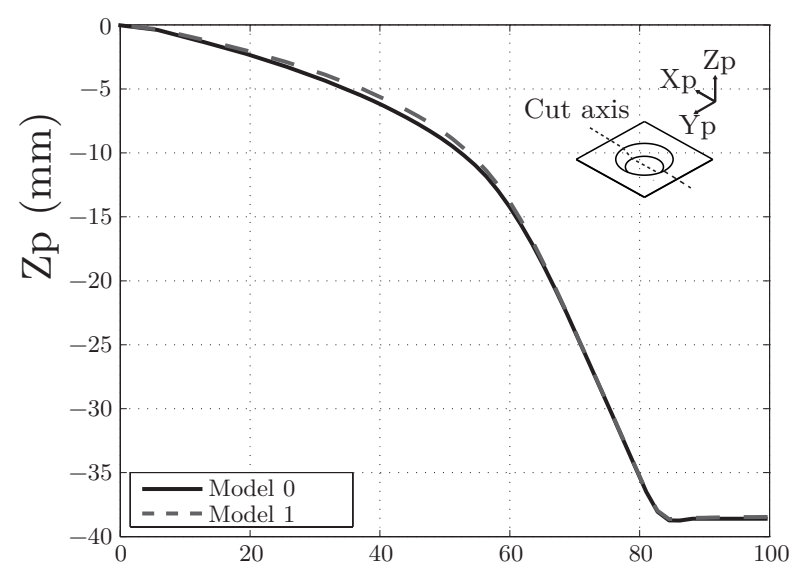

Distance along the cut axis $\mathrm{Xp}(\mathrm{mm})$

Fig. 9: Effect of the finite element type on the final geometry prediction

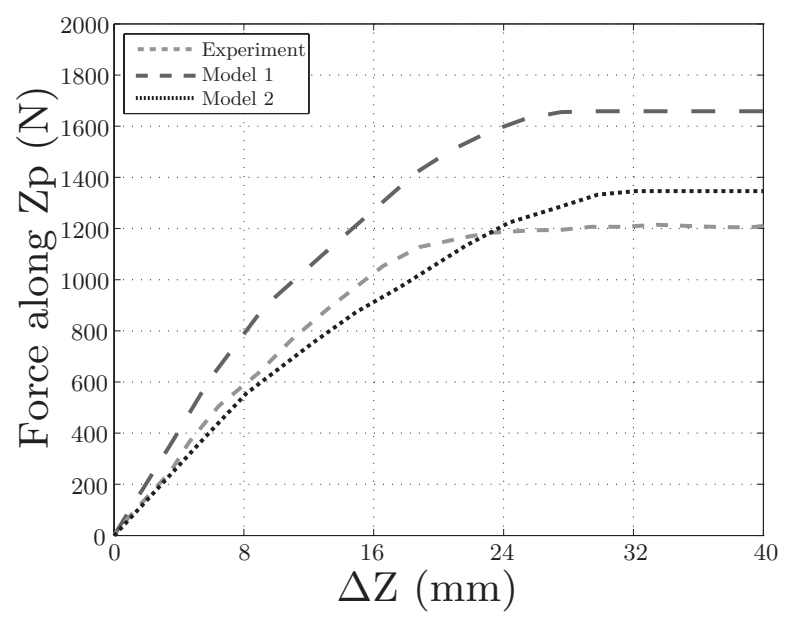

Fig. 10: Effect of the clamping model on the force $F_{z}$

Influence of the hardening law. The maximum reached plastic strain level is about $80 \%$ as it is shown in Figure 11. The effects of the choice of the hardening law on the force $F_{z}$ are depicted in Figure 12. The maximal difference between theses curves is about $150 \mathrm{~N}$ which represents $10 \%$ of the maximal value of the force. The Voce law gives a better correlation with experiments than the Ludwick law. Because no experimental setup has been made to identify the hardening law for large strain levels, the Voce law is chosen for the application of the correction of the tool path errors.

\section{Elasto-geometrical model of the robot}

The elastic modelling of the robot is performed using the analytical method proposed by Deblaise et al. [7]. This modelling has been already described in the RSPIF context by Belchior et al [8]. It consists in describing the elastic behavior of the robot as a unique elastic beam. The resulting identified elastic model allows to predict the TCP displacements induced by the elastic behavior of the robot structure over the workspace whatever the load applied on the tool. The predicted maximum and mean errors are respectively of $\pm 0.35 \mathrm{~mm}$ and $\pm 0.15 \mathrm{~mm}$ which remain compatible with the process requirements. 


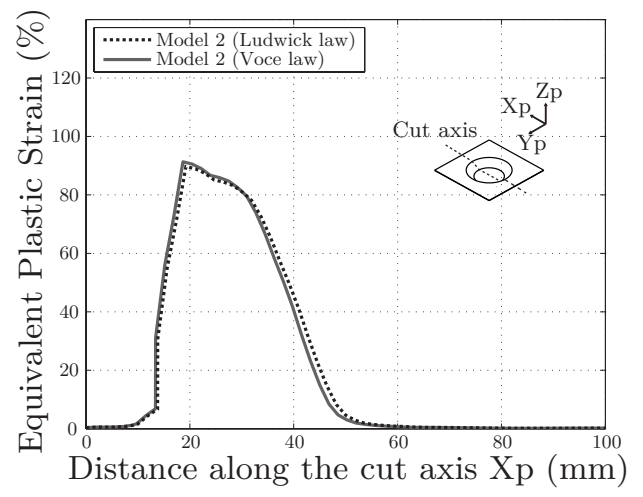

Fig. 11: Effect of the hardening law on the final strain prediction

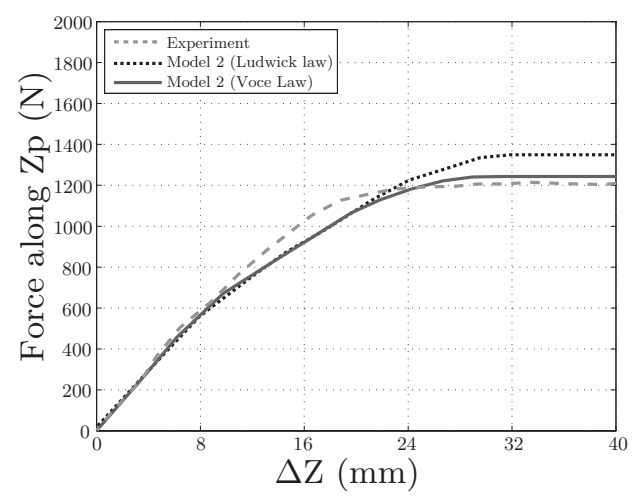

Fig. 12: Effect of the hardening law on the force $F_{z}$

\section{Coupling approach Process/Machine}

This approach consists in coupling the FEA of the forming process and the elasto-geometrical modelling of the robot. To perform this approach a post-processor is developed as in [1] (Figure 13).

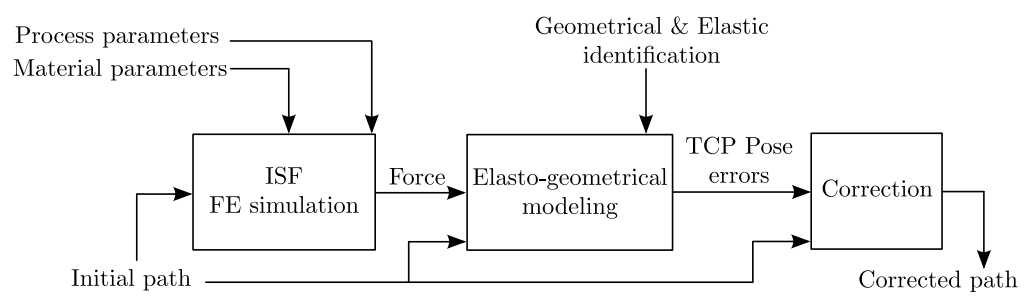

Fig. 13: Post-processor scheme

The process FE simulation performed with the ABAQUS software computes the forces required to form the part. The value of these forces is then used to calculate with the elasto-geometrical model the TCP pose errors induced by the elastic deformations of the robot structure. Then the corrected tool path is calculated. The efficiency of this post-processor is evaluated on the forming of the frustum cone previously described.

\section{Correction of the tool path errors in RSPIF}

A significant improvement of the geometrical accuracy is obtained (Figure 14). The difference between the final shape made with the milling machine and the one made with the robot is less than 1 $\mathrm{mm}$ when a correction is applied against approximately $4 \mathrm{~mm}$ without correction. This experimental results show the method relevance. The geometrical accuracy of the formed part is improved of $80 \%$.

\section{Conclusion}

In this paper the force prediction obtained by a FEA of RSPIF process is investigated. The influence of different FE model parameters (element type, modelling of the clamping system, hardening law) is studied. Based on this force prediction and on an elastic model of the robot, a coupling approach Machine/Process is proposed to correct the tool path errors for a RSPIF operation. The obtained experimental results show the method relevance since the geometrical accuracy of the formed part was improved of $80 \%$. 


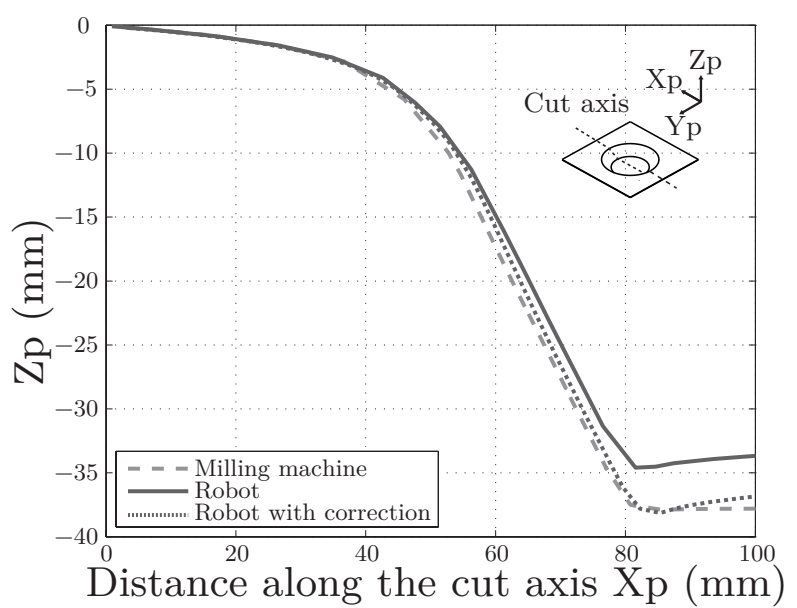

Fig. 14: FANUC S420iF modelling

\section{References}

[1] H. Meier, B. Buff, R. Laurischkat and V. Smukala: Technology In-creasing the part accuracy in dieless robot-based incremental sheet metal forming (CIRP Annals - Manufacturing Technology, 58:233-238, 2009).

[2] J. Verbert, R. Aerens, H. Vanhove and E. Aertbeliën and J.R Duflou: Obtainable Accuracies and Compensation Strategies for Robot Supported SPIF (Key Engineering Materials , 410-411:679687, 2009).

[3] C. Henrard, C. Bouffioux, P. Eyckens, H. Sol, J. Duflou, A. Van Bael, P. Van Houte, L. Duchne and A.M. Habraken: Forming forces in single point incremental forming: prediction by finite element simulations, validation and sensivity (Computational mechanics, 47:573--590, 2011).

[4] C. Bouffioux, C. Henrard, J. Gu, J. Duflou, A.M. Habraken and H. Sol: Development of an inverse method for identification of materials parameters in the single point incremental forming process (IDDRG, 2007).

[5] C. Zhang, L. Leotoing, D. Guines and E. Ragneau: Experimental and numerical study on effect of forming rate on AA5086 sheet formability (Materials Science and Engineering A, 527:967--972, 2010).

[6] S. Diot, D. Guines, A. Gavrus and E. Ragneau: Forming Process of a 5083 Aluminum Alloy. Constitutive Model Covering a Large Range of Temperature (International Journal of Forming Processes, 9:167--168, 2006).

[7] D. Deblaise, X. Hernot and P. Maurine: A systematic analytical method for PKM stiffness matrix calculation (IEEE International Conference on Robotics and Automation, pages 4213-4219, Orlando, Florida, USA, 2006).

[8] J. Belchior, M. Guillo, E. Courteille, P. Maurine, L. Leotoing and D. Guines: Offline compensation of the tool path deviations on robotic machining: Application to incremental sheet forming (Robotics and Computer Integrated Manufacturing, http://dx.doi.org/10.1016/j.rcim.2012.10.008, 2012). 